\title{
CORRIGENDUM
}

\section{Forty-five-year follow-up on the renal function after spinal cord injury}

\author{
M Elmelund, PS Oturai, B Toson and F Biering-Sørensen
}

Spinal Cord (2016) 54, 491; doi:10.1038/sc.2016.2

Correction to: Spinal Cord (2016) 54, 445-451; doi:10.1038/ sc.2015.242; published online 12 January 2016

Since the publication of this article, the authors have noticed that the horizontal axis of Figure 3 a was mislabelled. The correct version of the

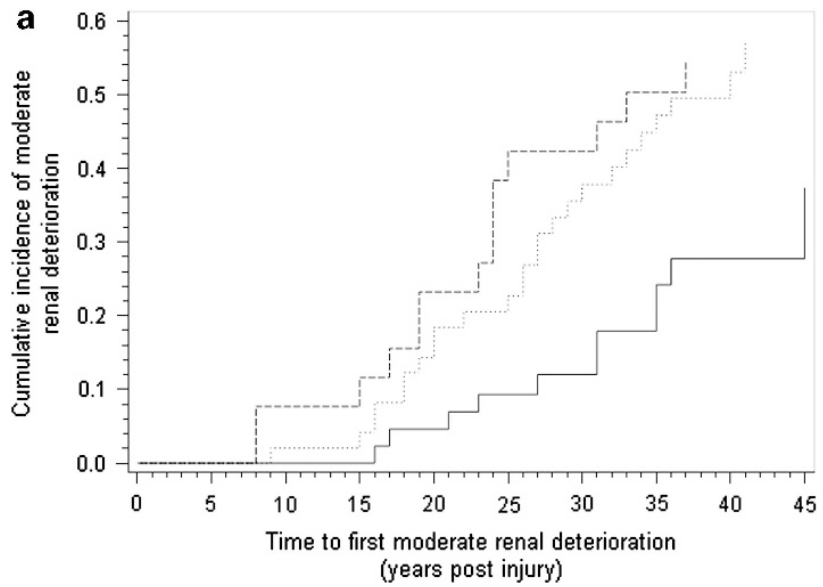

Figure 3 figure is below. The PDF and online versions of the article have been amended.

The authors apologize for any inconvenience caused. 